\title{
MULTICULTURAL EDUCATION AND COMMUNICATION COMPETENCES OF THE PUPILS IN A MULTIETHNIC CLASSROOM IN THE CZECH REPUBLIC
}

In accordance with new principles of curricular policy formulated in the National Program of Development of Education in the Czech Republic in 2004 the new system of curricular documents for education of pupils from three to nineteen years of age is given. The aim of the article is to describe general situation with this related and outline main tasks which wait the Czech educational system in the connection with these problems in immediate future.

\section{Introduction}

Adaptation of foreigners in a majority society is becoming an all-society issue due to the common trend of increasing migration. We may say the world is in a multicultural situation. This situation or an ongoing process impacts everyday life of an individual and brings forward new requirements for political and social strategies. An creasing migration is the fact that has impacted many democratic, economically developed countries. The trend still continues and indications show it cannot be stopped even by restrictions and repressions. Every society and every nation should aim at using its own cultural potential and protecting it against discrimination.

Also the Czech Republic is becoming a country where people of different origins, races, religions, morale and different opinions on the meaning of life meet more and more often. Therefore, it is necessary to focus more intensively on what is called multiculturalism in the traditional target countries of immigrants.

\section{Multiculturalism in the Czech Republic}

The concept of multiculturalism is not definite, though. It is interpreted differently in different contexts and its perception also changes in time. In the 60's and 70's the opinion prevailed that acknowledged differences between people and such differences were perceived as "normal". Nevertheless, such approach did not lead to tolerance, but brought forward the differences between people.

The beginning of the 80 's came up with the idea it was necessary to be tolerant and respect differences, which enrich us as we make one world together. Not everyone managed such approach as insufficient (and often just negative) information about those, who are different, did not make equal treatment for everyone possible.

The Slovak pedagogue V. Cabanová understands multiculturalism "as a cultural dialogue and common understanding in a symbiosis of multiple (at least two) cultures on the principle of equal with equal, independent with independent"(see page 44 in [5]).

The Encyclopaedia of Educational Research (New York 1982) states that "multicultural education is a preparation for social, political and economic reality the students live in culturally different contacts with people", while the "Pedagogic dictionary" (Prague 1998) understands multicultural education as "an effort to create people's ability to understand and respect other cultures than their own via educational programs."

The need to implement multicultural education to the Czech educational system implies from the constitutional concept of the Czech Republic as the country of "equal, free citizens"(see Preamble of the Constitution of the Czech Republic), whose "Basic rights and freedoms are guaranteed to all regardless their gender, race, skin colour, language, religion, political or other opinion, national or social origin, national or ethnic group, possession, kind or other position" (the Bill of basic rights and freedoms, article 3, paragraph 1).

Multicultural education is understood as a newly established (the 80 's of $20^{\text {th }}$ century) field of study, the main objective of which is to create equal opportunities for pupils (students) of different racial, ethnic and social classes and cultural groups.

Multicultural education thus not only takes over the content, concepts and paradigms of specialised interdisciplinary disciplines like ethnical studies, education of women, pedagogy and psychology,

\footnotetext{
* Jaromíra Šindelářová

Faculty of Education, J. E. Purkyně University, E-mail: sindelarova@pf.ujep.cz
} 
but mainly it actively and purposefully cooperates with them while complementing, specifying, generalising and reviewing them.

The issue of multicultural education has only been dealt with in the Czech educational system since 2001. The conflicts in interethnic symbiosis in our society proved to be of a broader basis and the long-term education concept must strive for deeper and broader prevention of arising of conflicts

In accordance with new principles of curricular policy formulated in the National Program of Development of Education in the Czech Republic (so-called White book) and stipulated in the Law on pre-school, basic, secondary, advanced vocational and other education, a new system of curricular documents for education of pupils from three to nineteen years of age is introduced in the educational system. Curricular documents are created on two levels: national and school.

The national level in the system of the documents is represented by the National Education Program and framework education programs (hereinafter as FEPs). The National Education Program defines initial education as a whole. FEPs define obligatory education frameworks for individual levels - pre-school, basic and secondary education.

The school level is represented by school education programs (hereinafter as SEPs), according to which education is realised in individual schools (when developing it, many schools use former education documents Elementary school, Primary school, Basic school). It must ensure equal access to education, specialised programs for pupils with specific needs and conditions for achieving key competencies of pupils.

The content of basic education is divided in BE FEP into nine education areas formed by a single education subject or multiple subjects with related contents; namely Language and language communication (Czech language and literature, Foreign language), Mathematics and its application, Information and communication technologies, Man and his world, Man and society (History, Citizenship education), Man and nature (Physics, Chemistry, Biology, Geography), Art and culture (Music, Arts), Man and health (Health, Physical education), Man and the world of work.

Basic education in the Czech Republic follows up on pre-school education and education in the family. This level is obligatory for the entire population of pupils in two (with follow-up content, organisation and didactics) education levels.

The concept of basic education on Level 1 (i.e. for pupils of first to fifth class) provides for easier transfer from pre-school education and family education to the obligatory, regular and systematic education. It is based on cognition, respect and development of individual needs, potentials and interests of every pupil (including pupils with special education needs). By its orientation towards children at the age of six to eleven it focuses mainly on education aspects of personal development of the pupil and emphasises full development of a specific cultural identity of the individual.
Basic education on Level 2 supports pupils in gaining knowledge, skills and habits that enable them to study independently and to create values and attitudes leading to sensible and cultivated behaviour, responsible decision making and respecting of the rights and freedoms of a citizen of our country and the European Union.

On both Level 1 and 2, basic education requires stimulating and creative environment that stimulates the most gifted pupils, supports the less gifted, protects and supports the weakest pupils and ensures optimum development of every child in accordance with its education potential via education (adjusted to individual needs). Friendly and open atmosphere motivates pupils to study, work and do activities they are interested in and it gives them room and time to learn actively and fully develop their personality.

During the basic education, pupils gradually acquire new qualities enabling them to continue their studies on $3^{\text {rd }}$ level schools, improve in their selected profession and continue their education throughout their lives and actively participate in social life.

Elements of multicultural education are present in the entire education process and they are most apparent in creating cooperative and communication competences of the pupils and students. All areas of the respective education level offer opportunities to apply the elements. The Framework Education Program does not specify the curriculum down to the level of individual years, and so Multicultural education is not further divided, either, as the purpose of multicultural elements is not to extend the amount of curriculum, but offer a broader perspective for presenting the content.

A new lingua-didactic concept designated as the communication method was being introduced in the lessons of Czech and foreign languages in the 70's of the last century and since then it has become more and more popular. Today, it plays a dominant role in language learning; social and situational embedding and conditionality of language communication are reviewed. The concept of competence (Noam Chomsky) is newly introduced and it is preferred over any other concepts like skills, qualifications, abilities, etc., with regard to compatibility of concepts on international level and also because its scope covers knowledge, skills, abilities as well as standpoints and values. The concept has embedded itself in Czech professional pedagogic literature and Czech public is also becoming aware of it.

\section{Key competences in the Czech education system}

The Czech education system also uses the concept of key competences upon request of the European Union. Key competences are defined as sets of knowledge, skills, abilities, standpoints and values important for personal development of an individual, its active involvement in the society and future life. The basic characteristic of key competencies in framework programs is their direct link to the content of individual education areas or subjects, respectively. Each content of a subject contributes to adoption and development of key competencies and such approach strengthens the activity character of the so-called expected outputs, which are a part 
of the education content and define the knowledge, skills, abilities, standpoints and values the pupils should achieve at the end of a specific stage. Such a way of linking key competencies to the education content corresponds with their concept on a higher level than subjects.

As language communication always takes place in a specific cultural, social and natural environment, it is also influenced by the environment. Therefore, modern lingua-didactics speaks of the socalled socio-cultural competence, which a student of a foreign language must also possess along with language, sociolinguistic, discursive, strategic and social competencies according to Jan van Ek.

Socio-cultural competence is given by characteristics of the respective society and culture and it is reflected in the behaviour of its members during communication. Speech is directly influenced by all facts creating socio-cultural competence and reflected in all language levels. Absence of their knowledge may significantly impact the speech, create major communication barriers that may lead to misunderstanding. Mastering socio-cultural competencies makes the communication act easier and faster.

In the first stage of education, a child needs to create prerequisites for continuous development of key competencies, development of learning abilities, problem solution, communication and continuous work in a group with involvement of all of its members. Selection of curriculum to be used as the means of acquiring competencies is defined by general education objectives. With regard to topics, the curriculum is divided in the individual education areas and its quantity should be adequate to the needs of development of competencies. The quantity of provided information must not create stress, which would block children's curiosity.

With regard to pupils on Level 2 (aged twelve to fifteen), we must consider the fact that development of their identity and moral feeling goes through a very complicated period and in a less straightforward way than on Level 1. Straightforwardness of their development is more strongly disrupted by numerous factors like enhanced ability of self-reflection, abstraction or intensive experience of their roles in a group of peers and in relations in general, low personal self-confidence, need for an alternative identity and identification with a group or disbelief in authorities.

Every pupil should be aware of his/her uniqueness, should be able to identify his/her weaknesses, but at the same time should be lead to being able to use his/her strengths in favour of others as well as be able to acknowledge their weaknesses and accept help from others. And this is one of the most difficult educational tasks a pedagogue must manage with his/her children.

The Framework Education Program for basic education puts an emphasis on general educational goals focusing primarily on achieving key competencies developing the personality of a pupil and potential of his/her further growth. It has been said in many discussions that progress in science and technology leads to excessive specialisation, but relatively little attention is paid to the fact that the same process is accompanied by the need of integration (of often very different disciplines, e.g. a doctor cannot function without chemistry or mathematics, urbanity without demography, economist without social psychology and manager without applied ethics). From this point of view, awareness of diversity of the world offers deeper basis for understanding of multicultural approaches and other contexts that seem necessary for all topics and all educational objectives in general. This approach is especially important on Level 1 of basic education.

In relation to achieving the key competencies, general educational objectives are virtually identical with the objectives of multicultural education. We may even say the specific objectives of multicultural education deepen and enrich the paths to the key competencies of a more permanent reach, e.g. change of anguish of a young pupil to dynamic self confidence the child has acquired thanks to communication and cooperative interactions in the classroom.

Multicultural education as a topic in FEP should contribute to development of the personality of pupils in two areas:

1. their knowledge, skills and abilities, in which it should give pupils basic knowledge of different ethnic and cultural groups living in the Czech and European society, develop the skill to orientate oneself in a plurality society and use intercultural contacts to enrich oneself and the others, teach pupils to communicate and live in a group with members of different socio-cultural groups, exercise their rights and respect the rights of others, understand and tolerate different interests, opinions and abilities of others, learn to accept another person as an individual with equal rights, realise that all ethnic groups and all cultures are equal and none is superior to another, develop the ability to learn and tolerate differences of other national, ethnic, religious, social groups and work with members of different socio-cultural groups, develop the skill to identify racial hatred and help prevent xenophobia, teach pupils to realise the potential impact of their verbal and non-verbal expressions, prepare pupils to bear responsibility for their actions, provide knowledge of some basic concepts of multicultural terminology such as, for example, culture, ethnic group, identity, discrimination, xenophobia, racism, nationality, intolerance, etc.

2. in the area of their standpoints and values e.g. help pupils create standpoints of tolerance and respect to different sociocultural groups via information, reflect the background of other socio-cultural groups and recognize them, help pupils realise their own identity, be themselves, reflect their own socio-cultural background, stimulate, influence and correct acting and values of pupils, teach them to perceive diversity as an opportunity to enrich, not as a reason for conflict, help them realise incompatibility of racial (religious or other) intolerance with principles of life in a democratic society, lead them to engagement when eliminating intolerance, xenophobia, discrimination and racism, teach them to perceive themselves as citizens who take active part in forming the society's attitude towards minorities. 


\section{Topics of Multicultural education}

Topics of Multicultural education are based on the actual situation at the school; they reflect current events in the school's municipality, current situation in the society. (Selection and realisation of the respective topic may be significantly influenced by an agreement of teachers, teachers and pupils, teachers and parents, etc.)

A. Cultural difference - uniqueness of every human being and his/her individual specialities; human being as an inseparable unity of physical and mental aspects, but also as a member of an ethnic group; getting to know one's culture; respecting specialities of various ethnic groups (especially foreigners or members of ethnic groups living in the school's municipality); basic problems of socio-cultural differences in the Czech Republic and Europe

B. Human relationships - the right of all people to live together and cooperate; maintain tolerant relationships and develop cooperation with other people regardless to their cultural, social, religious, interest or generation classification; relationships between cultures (mutual enrichment of different cultures, but also conflicts implying from their diversity); prejudices and stereotypes (causes and effects of discrimination); importance of integration of an individual in family, peer and professional relationships; application of the principle of good behaviour (basic moral standards); significance of quality of human relationships for harmonic development of personality; tolerance, empathy, ability of empathy in the role of another person; human solidarity, personal contribution to involvement of pupils from different cultural environment in the class

C. Ethnic origin - equality of all ethnic groups and cultures; diversity of people, but also their equality; position of national minorities; basic information about various ethnic and cultural groups living in the Czech and European societies; different ways of life, different thinking and perception of the world; racial intolerance - its identification and reasons

D. Multiculturalists - multiculturalism of the current world and the expected development in the future; multiculturalism as the means of common enrichment; specific aspects of languages and their equality; listening to others, communication with members of different socio-cultural groups, open approach to diversities; importance of using a foreign language as a tool of communication and lifetime education

E. Principle of social conciliation and solidarity - responsibility and contribution of every individual for elimination of discrimination and prejudices towards ethnic groups; non-conflict life in a multicultural society; active participation in changing the society, taking into account the needs of minorities; issue of human rights, basic documents

Multicultural education goes through all educational areas, it is closely linked especially to the educational area Language and Language Communication as it teaches pupils to communicate and live in a group with members of different ethnic groups, respect their specialities, understand and tolerate different interests, opinions and abilities. This area has a crucial position in the education process, the content of which is realised in subjects "Czech Lan- guage and Literature, Foreign Language and Second Foreign Language. (Second Foreign Language is defined for school year 2011/ 2012 as a complementary education subject with the disposition of 6 lessons on Level 2 of Basic School, which means the school must offer this subject to all pupils in the form of obligatoryoptional subject.)

Foreign Language and Second Foreign Language provide a living language basis and prerequisites for communication of pupils within integrated Europe and the world, help reduce language barriers of Czech pupils and thus contribute to increased mobility of individuals. The requirement for education of Czech pupils in foreign languages are clearly formulated in BE FEP, based on Common European Reference Framework, which provides general basis for preparation of language syllabuses, policies for preparation of curriculum, exams, textbooks, etc. in the entire Europe, and it also specifies what pupils and students must learn to use the language for communication and what knowledge and skills they must develop to be able to act effectively. Levels of command of a foreign language are defined. Education in a Foreign Language heads for achieving level A2, education in Second Foreign Language heads for achieving level A1. (Common European Reference Framework for languages defines communication (linguistic, sociolinguistic, pragmatic) and general (assuming knowledge of socio-cultural environment of the countries where the studied language is spoken) competences as target competences of language education.

Level A2: The pupil understands sentences and frequently used expressions relating to areas that directly affect the pupil (e.g. basic information about him/herself and his/her family, shopping, geography and employment). $\mathrm{He} /$ she can communicate via simple and common tasks requiring simple and direct exchange of information about known and common facts. He/she can describe his/ her family, close surroundings and matters regarding his/her most urgent needs in a simple way.

Level A1: The pupil understands everyday common expressions and very basic phrases, the objective of which is to meet the specific needs, and he/she can use such expressions and phrases. He/she can introduce himself/herself, ask simple questions regarding information of personal character, e.g. about his/her home, people he/she knows, things he/she owns and he/she can also answer such questions. He/she can communicate in a simple way if the partner speaks slowly and clearly and if he/she is willing to help.)

The number of basic school pupils, whose mother tongue is not Czech, is continuously increasing, e.g. according to the information the from Information Institute for Education, there were 12,279 foreigners in basic education, of which 2,616 of the EU countries.

As one of the "objectives of political organisation of the Council of Europe is to increase awareness of language diversity of current multicultural Europe"(see page 161 in [6]), also the Czech education system had to react to the requirements of the EU legislation by numerous system changes and reforms. One of 
the objectives of our education according to the Framework Education Programs (hereinafter as FEP) is to "lead pupils to tolerance and discretion to other people, their cultures and spiritual values, teach them to live together with other people". This is a long-term process and according to V. Cabanová "the target situation of accepting and tolerating diversities requires long-term activity in educational institutions" - see page 46 in [5].

The former education law, Act No. 29/1984 Coll., on the system of basic schools, secondary schools and advanced vocational schools did not expressly speak of the obligation to provide foreigners with access to education under equal conditions to those of Czech citizens, but many international contracts were valid here protecting citizens (not only EU citizens, but all the foreigners) against discrimination and at the same time they guaranteed equal rights to education. As an example we may give the Children Rights Agreement (article 28), Additional protocol to the Convention of Protection of Human Rights and Basic Freedoms (article 2) or General Declaration of Human Rights (article 26).

The new education law No. 561/2004 Coll. effective since January 1, 2005 generally speaks of education of foreigners in section 20. Everybody is granted the right of access to basic, secondary and advanced vocational education under the conditions equal to those of citizens of the Czech Republic, i.e. free of charge. Equal access to education and education services as citizens of the Czech Republic is granted to citizens of other member countries of the European Union and their family members, but also to foreigners from third countries with the status of long-term resident in the European Community on the territory of the Czech Republic, or to those granted the status of long-term resident in another member country of the European Union and they were granted a residence permit on the territory of the Czech Republic.

Children of citizens of these countries are given room for their education in our education system by having the right to participate e.g. in free preparation for inclusion in basic education including lessons of Czech language adapted to the needs of the pupils, and if possible in cooperation with the country of origin of the pupil support teaching of the language and culture of the country of origin, coordinated with standard education at our schools free preparation and training of pedagogues providing for the education is the responsibility of Regional Offices (in coordination with the founder of the school according to the place of residence of the pupil). Teachers in the individual regions of our country have already been trained - approximately 25 teachers have been trained in every region. The ministry defines the form, content and organisation of the free preparation. Language preparation currently consists of at least seventy lessons for the maximum of six successive months of a school year; pupil-stranger is posted in the preparatory course based on a written application by his/her legitimate representative. The headmaster of the school is obliged to post the pupil in the preparation within thirty days. The expected output is given in the Framework Education Program for basic education and it heads towards achieving level A2. Lower limits are defined for adults, though and, in my opinion, they do not reflect the specific needs of children for their inclusion in basic education. With regard to the number of lessons (70) compared to the expected output of a Czech pupil in Foreign Language (six years) and an adult foreigner (lower limit A1: 80-150 lessons), level A1 would suit better, although according to the words of the author of this level, M. Hádková "A1 includes minimum of grammar, which is presented just as an instrument, not an objective"(see page 165 in [6]).

If the legitimate representative of a pupil-foreigner does not ask the headmaster of the school, which every child between the age of 6 and 15 has to attend, for language preparation or if it is impossible to attend the language preparation due to long distance, the pupil-foreigner is posted to a Czech class which becomes a multiethnic class.

Mechanical posting of pupils by gender seems inadequate, because proper posting is not based only on age of a pupil-immigrant, but also his/her knowledge of the education language, i.e. Czech. A large difference (more than two years) between the age of a foreigner and other classmates is not desirable either and it leads to problems of social character. Duration of stay of the child in the Czech environment before going to school is important.

Experience shows the best age for developing the communication abilities of a child from an ethnic minority is pre-school age. Younger school children (under 9 years) have smaller problems with switching to communication in Czech than older school children and secondary school students.

A large influence on integration of a foreigner in the Czech education system is that of a motivation to learn. Families intending to stay in the Czech Republic long-term and having positive attitude towards education provide their children with private courses and Czech babysitters (e.g. Chinese and Vietnamese traders). Pupilsforeigners living in larger communities with their parents and relatives have a negative attitude towards Czech language as the means of communication as they do not need it, in fact. Rich parents rather hire an interpreter instead of learning Czech and they lead their children towards the same attitude. They are very often willing to drive their children tens of kilometres to schools teaching in their mother tongue or a so-called big language (e.g. English, French or German).

Influence of the child's mother tongue may not be neglected either. Little communication problems are indicated by pupils with Slavonic mother tongues, although similarity of languages may have a negative effect at the end.

Also the mediation language, i.e. knowledge of a communication code common to the pupil and the teacher (mother tongue of pupil-foreigner, or a world language he/she commands well) may significantly speed up the initial communication with a foreigner and change to communication in Czech. Direct method looks to slow for beginners and it may be applied to more advanced pupils. 


\section{Conclusion}

Schools in the Czech Republic try to avoid isolation of a pupilforeigner in a class (it is good to appoint a Czech classmate as a guide), so that he/she is continuously involved in education as well as non-school activities and gets an opportunity to present him/herself positively (e.g. by cultural values of his/her ethnic group). Individual programs and approach should be applied to the maximum possible extent. Priority should clearly be given to aspects accentuating communication command of Czech language including the so-called socio-cultural competence - see pages 9 - 12 in [9], subsequent differentiation between non-literary and literary forms, more impact on spoken language (paying special attention to phonetics and phonology from the very beginning as pupils-foreigners are influenced by phonetic-phonologic systems of their mother tongues), then on written language.

\section{References}

[1] The new education law, Act No. 561/2004 Coll on pre - school, basic, middle, higher, special and other (in Czech), Praha, 2004, Available on <www. msmt.cz> [liable 10.10. 2006]

[2] Framework Education Program for Basic Education (in Czech), Praha, 2004, Available on <www.vuppraha.cz> [liable 10. 9 2006]

[3] Threshold Level for Czech as a foreign language, 2001, Cambridge

[4] BARŠA, P.: Political theory of multiculturalism (in Czech), Brno, 1999

[5] CABANOVÁ, V.: Culture and balancing of cultural differences in school education (methods and strategies endorsing school fruitfulness) -in Slovak, Prešov, 2006

[6] HÁDKOVÁ, M.: European models in foreign language learning, Bohemistyka, 3/2006, Ratiborz.

[7] HÁDKOVÁ, M., ŠINDELÁŘOVÁ, J.: Multicultural Classroom Interaction, in electronic form to Languages of School Education Division of Modern Languages of the Council of Europe (www.coe.int/t/dg4/linguistic/Source/Hadkova), 2006

[8] PRŮCHA, J.: Intercultural psychology (in Czech), Praha, 2004

[9] ŠÁRA, M.: Threshold Level 1990 - Threshold Level: Czech for Foreigners, Praha, 2002

[10] ŠINDELÁŘOVÁ, J.: Socio-cultural foul territory of pupils and students-immigrants incoming from countries with different culture (in Czech), Ústí nad Labem, 2005

[11] ŠIŠKOVÁ, T.: Education towards tolerance and against racism (in Czech), Praha, 1998 [12] Encyclopedia of Educational Research, New York, 1982 